\title{
A Survey study on the Reading habits among English Major Students of Sherubtse College: Issues and Perspectives
}

\author{
Rinchen Dorji \\ Rinchendorji.sherubtse@rub.edu.bt \\ Sherubtse College, Royal University of Bhutan, Bhutan
}

\begin{abstract}
The practice of reading both for academic purposes and pleasure is largely agreed to have diminished over the years mainly because of advancements in social media technology. This paper thus examined the reading habits in general among English major students at Sherubtse College, Royal University of Bhutan. For data collection, a questionnaire with nine items was designed and administered to 106 English major students with gender and the year of study as the moderating variables. The questionnaire investigated the students' general attitudes towards reading, the reasons they read, the average time they spend on reading, the challenges they faced in reading, and the effects of social media on their reading habits. In addition, informal interviews were conducted to verify and triangulate the responses received from the participants. Both these quantitative and qualitative data revealed interesting insights into the reading habits of the students in question. The results are discussed and recommendations provided at the end.
\end{abstract}

Keywords: Reading habits, gender, social media, academic reading.

\section{Introduction}

Reading has long been considered an indispensable part of learning. Apart from contributing to academic success through the development of critical thinking skills, reading also broadens the horizons of one's knowledge. Hence, it is given utmost importance, and students in schools and universities are encouraged to engage themselves in meaningful readings.

In Bhutan, the inspiration to engage oneself in reading comes from His Majesty the King himself. His Majesty has repeatedly said that the pursuit of knowledge must be lifelong and thus we must read about everything around us, and not just subjects that interest us. Regarding the importance of reading, the year 2015 was declared as the 'National Reading Year' in Bhutan and it was launched by His Majesty the King himself in Thimphu on December 9, 2014. It was dedicated to His Majesty the fourth king as part of his $60^{\text {th }}$ birth anniversary. The Prime Minister's State of the Nation report on July 5, 2016 pronounced the 'National Reading Year' as a big success and reported that a total of 2,511,512 books were read in just one year. On average each student read about two books per month. This indeed was a big success for the whole nation. Such activities are important and timely especially in the backdrop of rapid growth in social media technology where more people now seem to get themselves engaged with technological gadgets, discarding the importance of the tradition of reading.

However, it is generally perceived that the reading habits of students around the world have diminished compared to the past. A study such as this thus merits to be carried out to learn the issues and perspectives of the students with regard to reading so that more suitable, interesting and meaningful approaches to reading can be explored to let the students cultivate the habit of reading.

Vol. 4, Issue. 3, (2020). pp. 1-11

International Journal of Information Technology and Language Studies (IJITLS).

http://journals.sfu.ca/ijitls 


\section{Literature Review}

Despite unprecedented developments in technology, reading is still regarded as the best source of knowledge. Many studies have thus been carried out on reading habits from multiple dimensions such as gender (Scales \& Rhee, 2001; Synder, 1981), age (Fusco, 1986; Celik, 2019), socio-economic conditions (Le et al., 2019; Devarajan, 1989), and family background (Greaney, 1986; Baker et al., 1997; Yusof, 2010).

Reading is closely related to personal and intellectual growth that leads to a person's success in life. Individuals with good reading habits have the chance to widen their mental horizons and to multiply their opportunities (Loan, 2009). Further, Arthur et al. (2018) maintain that reading is the fundamental factor that determines the foundation of prominence in people's lives irrespective of status, gender, and age. Similarly, Chhetri and Rout (2013) argue that reading, which is a long-term habit starting with the very early ages, is the prominent gateway to the knowledge room. Connecting good reading habits with academic success, Noor (2011) claims that reading is valued as the most important academic language skill for all second and foreign language learners as it enables learners to become more competent in their subject matters. Likewise, the issue of reading whether it is for learning or leisure is important since it helps broaden young people's experiences and knowledge (Green, 2002).

Unfortunately, however, the reading habits among students is generally seen to be degrading. In most tertiary institutions, learners do not read, even the few who read, only do so as a means of passing their examinations (Paul et al. 2012). Adding on, Philip (2009) maintains that reading habit often tends to be associated with course work and examinations, but rarely with pleasure. Agreeing with these claims, (Oseman, 1977; Cabral and Tavares, 2002; Gunasekara, 2002; Akabuike and Asika, 2012) all discovered that majority of the students read only to pass examination and quiz and not for pleasure. Further, Cheah (1998) noted that while students will not hesitate to read school related materials, getting them to become life-long readers and read for the pleasure remains an uphill task. Similarly, an international survey has shown that majority of children from twelve developing countries revealed that they read for passing examinations (Books Aid International, 2003 as cited in Chhetri and Rout, 2013).

Wagner (2002) asserts that reading habit is often considered in terms of the amount of materials being read, the frequency of reading as well as the average time spent on reading. While numerous studies focusing on these and other areas of reading have been conducted both in schools and colleges around the world, very few studies have been carried out in the context of Bhutan. This paper thus studies the general attitude towards reading and reading habits of students in a college in Bhutan.

\section{Research design and Methodology}

The study was carried out at Sherubtse College, Royal University of Bhutan using mixed-method approach. The population of the study included first, second and third year English major students from three programs. A pre-set structured questionnaire was distributed among the participants for data collection. Out of the total 205 English major students, 106 (51.7\%) responded to the questionnaire. Relevant literature were reviewed in addition to conducting informal interviews with some random participants for qualitative data.

\section{Research aims and Questions}

The main aim of the research was to ascertain the English major students' reading habits at Sherubtse College. To address this aim, the following research questions were raised

1. What do students think about reading?

2. Does reading habit differ among different gender groups?

3. How much time do students spend on reading?

4. What are the challenges students face in reading? 
5. Could tutors play a role in influencing the students to cultivate reading habits?

\section{Results and Discussion}

This section presents the whole analysis and data findings on students' reading habits at Sherubtse College. The data collected was analyzed using simple frequency and percentage, and cross-tabulation of the moderating variables of gender and year of study.

\begin{tabular}{|c|c|c|c|c|}
\hline \multicolumn{5}{|c|}{ Total Year-wise Participants } \\
\hline \multicolumn{2}{|c|}{ Participants } & Frequency & Total & Percentage \\
\hline \multirow{2}{*}{ Year 1} & Male & 13 & \multirow{2}{*}{41} & \multirow{2}{*}{38.7} \\
\hline & Female & 28 & & \\
\hline \multirow{2}{*}{ Year 2} & Male & 6 & \multirow{2}{*}{21} & \multirow{2}{*}{19.8} \\
\hline & Female & 15 & & \\
\hline \multirow{2}{*}{ Year 3} & Male & 15 & \multirow{2}{*}{44} & \multirow{2}{*}{41.5} \\
\hline & Female & 29 & & \\
\hline \multicolumn{2}{|c|}{ Total } & 106 & 106 & 100 \\
\hline \multicolumn{5}{|c|}{ Total Gender-wise participants } \\
\hline \multicolumn{2}{|c|}{ Participants } & Frequency & \multicolumn{2}{|c|}{ Percentage } \\
\hline \multicolumn{2}{|c|}{ Male } & 34 & \multicolumn{2}{|c|}{32.1} \\
\hline \multicolumn{2}{|c|}{ Female } & 72 & \multicolumn{2}{|c|}{67.9} \\
\hline \multicolumn{2}{|c|}{ Total } & 106 & \multicolumn{2}{|c|}{100} \\
\hline
\end{tabular}

Table 1. Participants

As shown in table 1, the overall, total male participants in the survey were $34(32.1 \%)$ and the total female participants were 72 (67.9\%). Year wise, the participants were $41(38.7 \%)$ from first year, 21 $(19.8 \%)$ from the second year, and $44(41.5 \%)$ from the third year.

\begin{tabular}{|c|c|c|c|c|c|c|}
\hline \multirow[b]{2}{*}{ Responses } & \multicolumn{3}{|c|}{ Year of study } & \multicolumn{2}{|c|}{ Gender } & \multirow[b]{2}{*}{ Total } \\
\hline & Year 1 & Year 2 & Year 3 & Male & Female & \\
\hline It is fun & $20(48.7 \%)$ & $6(28.5 \%)$ & $12(27.2 \%)$ & $7(20.5 \%)$ & $31(43 \%)$ & 38 \\
\hline It is boring & $3(7.3 \%)$ & 0 & $3(6.8 \%)$ & $2(5.8 \%)$ & $4(5.5 \%)$ & 6 \\
\hline It is time- wasting & 0 & 0 & 0 & 0 & 0 & 0 \\
\hline $\begin{array}{l}\text { It is irrelevant in the digital } \\
\text { world }\end{array}$ & $1(2.4 \%)$ & $1(4.7 \%)$ & $1(2.2 \%)$ & $1(2.9 \%)$ & $2(2.7 \%)$ & 3 \\
\hline It is knowledge-giving & $17(41.4 \%)$ & $14(66.6 \%)$ & $28(63.6 \%)$ & $24(70.5 \%)$ & $35(48.6 \%)$ & 59 \\
\hline Total & & & & & & 106 \\
\hline
\end{tabular}

Table 2. Respondents' attitude towards reading

Table 2 displays the general attitude of the respondents towards reading. Alexander \& Filler (1976) define attitude to reading as 'a system of feelings related to reading which causes the learner to approach or avoid a reading situation' (p. 1) or as 'a state of mind, accompanied by feelings and emotions that make reading more or less probable' (Smith, 1990, p.215). In the current study, more than a half of second and third year respondents $(66.6 \%$ and $63.3 \%)$ respectively felt that reading was great for knowledge while $48.7 \%$ of the first year students felt that reading was rather fun as against only $28.5 \%$ of second years and $27.2 \%$ of third year students. This indicates that while the senior students are more into academic reading, first year students are more into pleasure reading.

On the gender front, female respondents seem to engage more in pleasure reading (43\%) than male (20.5\%). Many earlier studies (Askov \& Fischbach, 1973; Coles \& Hall, 2002; Kush \& Watkins, 1996; McKenna et al., 1995; Sainsbury \& Schagen, 2004 and Smith, 1990) also found that girls have a more 
positive attitude to pleasure reading than boys. Male respondents tend to engage more in academic reading, as the majority $(70.5 \%)$ of the males responded that reading was great for knowledge as opposed to only $48.6 \%$ among female respondents. Unfortunately, however, through an informal interview, it was found that boys engaging in academic reading meant that they read only tutors' notes and prescribed texts.

\begin{tabular}{|c|c|c|c|c|c|c|}
\hline \multirow[b]{2}{*}{ Responses } & \multicolumn{3}{|c|}{ Year of study } & \multicolumn{2}{|c|}{ Gender } & \multirow[b]{2}{*}{ Total } \\
\hline & Year 1 & Year 2 & Year 3 & Male & Female & \\
\hline I need to pass my exams & $6(14.6 \%)$ & $4(19 \%)$ & $6(13.6 \%)$ & $5(14.7 \%)$ & $11(15.2 \%)$ & 16 \\
\hline I am forced to read & $1(2.4 \%)$ & 0 & $6(13.6 \%)$ & $1(2.9 \%)$ & $6(8.3 \%)$ & 7 \\
\hline Reading is my passion & $\begin{array}{c}20 \\
(48.7 \%)\end{array}$ & $\begin{array}{c}12 \\
(57.1 \%)\end{array}$ & $\begin{array}{c}18 \\
(40.9 \%)\end{array}$ & $18(52.9 \%)$ & $32(44.4 \%)$ & 50 \\
\hline My tutors inspire me to read & $\begin{array}{c}14 \\
(34.1 \%) \\
\end{array}$ & $5(23.8 \%)$ & $\begin{array}{c}14 \\
(31.8 \%) \\
\end{array}$ & $10(29.4 \%)$ & $23(31.9 \%)$ & 33 \\
\hline \multicolumn{6}{|l|}{ Total } & 106 \\
\hline
\end{tabular}

Table 3. Reasons for reading

On being asked their reasons for reading, around half of the respondents chose reading to be their passion: first years: $48.7 \%$, second years: $57.1 \%$ and third years: $40.9 \%$. Even gender-wise, $52 \%$ of the male and $44.4 \%$ of the female respondents said that reading was their passion. Only $14.7 \%$ males and $15.2 \%$ females responded that they read only to pass exams. This is in contrast to many earlier research (Oseman, 1977; Cheah, 1998; Cabral and Tavares, 2002; Gunasekara, 2002; Philip, 2009; Paul et al., 2012; Akabuike and Asika, 2012; Chhetri and Rout, 2013) who found that most students read only to pass their exams.

Since 'tutors' inspiration' was chosen as the second top reason for students to read, it may be noted that some tutors are doing a great job in inspiring the students to read. Research have consistently found that teachers play a big role in motivating children to become avid readers. When teachers have positive attitude towards reading and reading habit, students eventually get motivated towards reading (Manohar, 2016). Further, Jose and Raja (2011) maintain that teachers are the prime source for students to cultivate the reading habit. They can execute this task only when they have the competence to play their role effectively. Hence it is very important for teachers to cultivate a reading habit themselves first so that they can motivate their students to read.

Through the informal interviews that were conducted to find out how tutors inspired students to read, it was found that some tutors dedicated few minutes often in class to talk about books they were reading and also encouraged the students to do the same. This inspired the students to get books of their choice and read them so that they could give book talks in the class. With regards to reading prescribed books, interviewees generally agreed that their compliance in reading depended on how far the tutors tested their reading. They said that tutors who constantly asked questions to test their reading made them to read for fear of embarrassment in the class while they hardly read texts taught by tutors who never quizzed them. This confirms what Clump et al. (2004) found- that reading compliance almost tripled when students knew they were about to be tested on a reading. Burchfield and Sappington (2000) thus urged professors to place greater emphasis on reading compliance by giving random quizzes. 


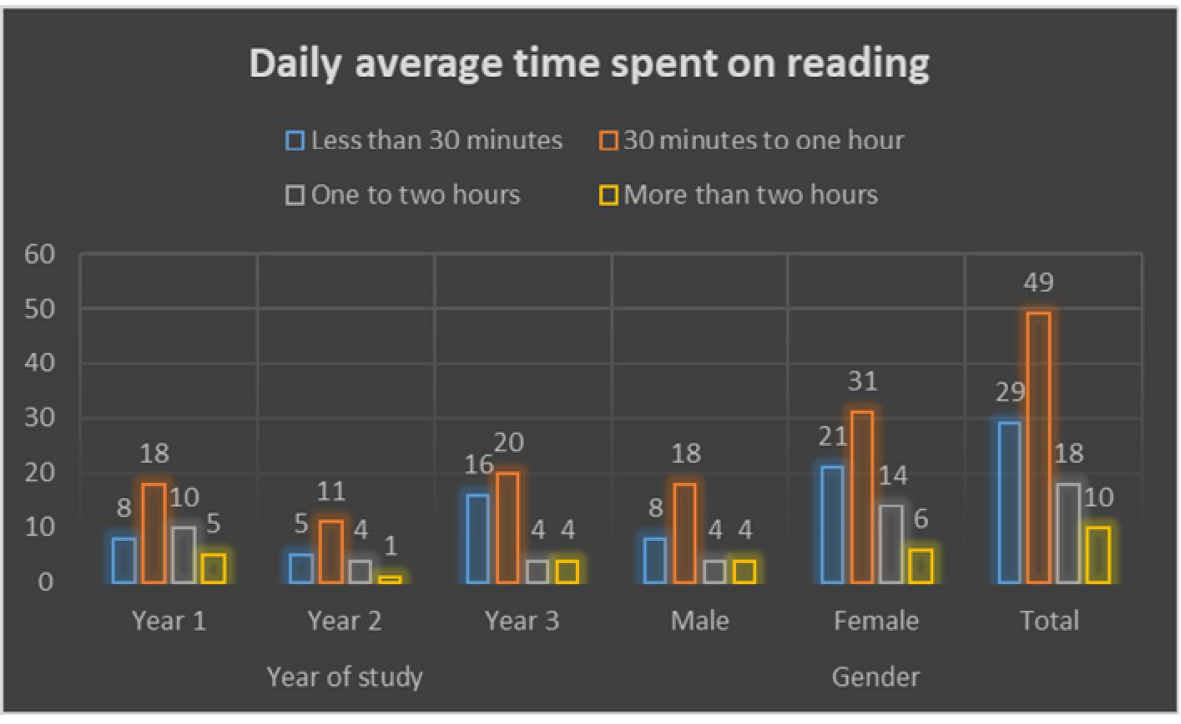

Figure 1. Average daily time spent in reading

It was heartening to note that almost half of the respondents reported spending between 30 minutes to one hour daily on average in reading, which works out to be between 3.5 to 7 hours of reading every week. This is better than many other similar studies conducted before. Hastings and Henry (2006, as cited in Loan, 2012) observed that more than half of the students, which is (56\%) spend less than half an hour a day on reading. Likewise, Gallik (1999) found that $63 \%$ read 2 hours and less weekly while only $13 \%$ read 6 hours and more. However, a worrying response was that there were also some respondents from all three years of studies who spent less than 30 minutes in reading. This would include some people who did not read at all. In terms of gender, 21 (29.1\%) female respondents who read less than 30 minutes every day were slightly higher than those of males at 16 (23.5\%). This was in contradiction to what Stenberg (2001) claimed, that women read more than men.

\begin{tabular}{|l|c|c|c|c|c|c|}
\hline \multirow{2}{*}{\multicolumn{1}{c|}{ Responses }} & \multicolumn{3}{|c|}{ Year of study } & \multicolumn{2}{c|}{ Gender } & \multirow{2}{*}{ Total } \\
\cline { 2 - 7 } Improved & Year 1 & Year 2 & Year 3 & Male & Female & 36 \\
\hline Deteriorated & $11(26.8 \%)$ & $11(52.4 \%)$ & $14(31.8 \%)$ & $15(44.1 \%)$ & $21(29.2 \%)$ & 37 \\
\hline Hasn't changed & $11(26.8 \%)$ & $4(19 \%)$ & $22(50 \%)$ & $7(20.6 \%)$ & $30(41.7 \%)$ & 33 \\
\hline Total & $19(46.3 \%)$ & $6(28.6 \%)$ & $8(18.2 \%)$ & $12(35.3 \%)$ & $21(29.2 \%)$ & 3 \\
\hline
\end{tabular}

Table 4. Change in reading habits

The present question was intended to find out how the reading habits of the students have changed after joining college. While almost half of the first year students $(46.3 \%)$ said their reading habits have not changed, more than fifty percent of the second year students (52.4\%) responded having improved. The worrying finding from the question, however, was the response from the third year students. Fifty percent of the students in question said that their reading habits have deteriorated. Gender-wise, more male respondents had an affirmative answer of having improved at more than forty four percent while more than forty one percent of the female respondents said their reading habits have deteriorated.

In trying to find out the reasons why their reading habits have deteriorated after joining college, an informal interview was conducted among few third year students comprising both girls and boys. The main reason for this deterioration according to the interviewees was the difference in the academic culture of school and college. All the participants agreed that in schools, they were required to maintain a reading portfolio, show to the teachers and talk on the books they have read which were then marked and grades given. Adding on, the participants also cited that in schools, there were lots of literary activities 
such as debates, elocution, quiz etc. which required them to read in preparation for the competitions. All these, they said, motivated and kept them engaged in reading. In college, however, they reported that none of these things happens, which ultimately led them to lose interest in reading. Most of the participants agreed that besides reading the summaries of the prescribed texts from the internet, they hardly read any other books. Thus, Brydolf's (2007) argument that most individuals never finish reading a fiction book from cover to cover after leaving school is found to be true.

\begin{tabular}{|l|c|c|c|c|c|}
\hline \multirow{2}{*}{\multicolumn{1}{c|}{ Responses }} & \multicolumn{3}{|c|}{ Year of study } & \multicolumn{2}{c|}{ Gender } \\
\cline { 2 - 5 } & Year 1 & Year 2 & Year 3 & Male & Female \\
\hline Lack of time & $29(70.7 \%)$ & $9(42.9 \%)$ & $17(38.6 \%)$ & $18(52.9 \%)$ & $37(51.4 \%)$ \\
\hline Lack of reading materials & $8(19.5 \%)$ & $3(14.3 \%)$ & $8(18.2 \%)$ & $11(32.4 \%)$ & $8(11.1 \%)$ \\
\hline Lack of interest & $5(12.2 \%)$ & $6(28.6 \%)$ & $9(20.5 \%)$ & $6(17.6 \%)$ & $14(19.4 \%)$ \\
\hline Lack of motivation to read & $3(7.3 \%)$ & $8(38.1 \%)$ & $16(36.4 \%)$ & $11(32.4 \%)$ & $16(22.2 \%)$ \\
\hline
\end{tabular}

Table 5. Challenges in reading

This was a multi-response question intended to find out what the main challenges of students in reading were. In her study, Hoeft (2012) reported that most students cited "too busy" as their top reason for being a noncompliant reader. Similarly, as anticipated, even in the current study 'Lack of time' was chosen as the top challenge the respondents faced in reading. Majority $(70.7 \%)$ of the first year students said the main challenge they faced in reading was the lack of time while only $7.3 \%$ said lack of motivation was the main challenge. Even in terms of gender, both males (52.9\%) and females (51.4\%) reported 'lack of time' as the top challenge. An informal interview conducted among few first year students revealed that having come from schools and transitioned to university education only a couple of months ago, they found difficulty in coping with new ways of teaching and learning at the university. They said that selflearning at the university was a new thing for them and that it was taking a lot of time for them to catch up with the lessons. This, they said left them with little time for other readings.

Both second and third year students also chose lack of time as the main challenge in reading (42.9\%) and (38.6\%) respectively, In an informal interview, almost all the participants from second and third year said that 'lack of time' was their main challenge because of many assignments they had to write in a semester, which runs to five months. On being asked how many assignments they wrote in a semester on average, they revealed that they have five modules each semester and they had to do two assignments in each module, which averaged to two assignments every month besides being engaged in class tests, presentations and seminars. While this could be true, a worrying response, however, was their (second and third year) students' choice of 'lack of motivation to read' (38.1\% of second years and $36.4 \%$ of third years) as one of the main challenges as opposed to only $7.3 \%$ of the first year respondents. If this is true, then it is a matter of concern as it would mean that first year students in college lose motivation to read as they move onto final years of their studies. This however validates the arguments of (Kush \& Watkins, 1996; McKenna et al., 1995; Sainsbury \& Schagen, 2004) that there is evidence that for both boys and girls, attitudes to reading become more negative as children get older. 


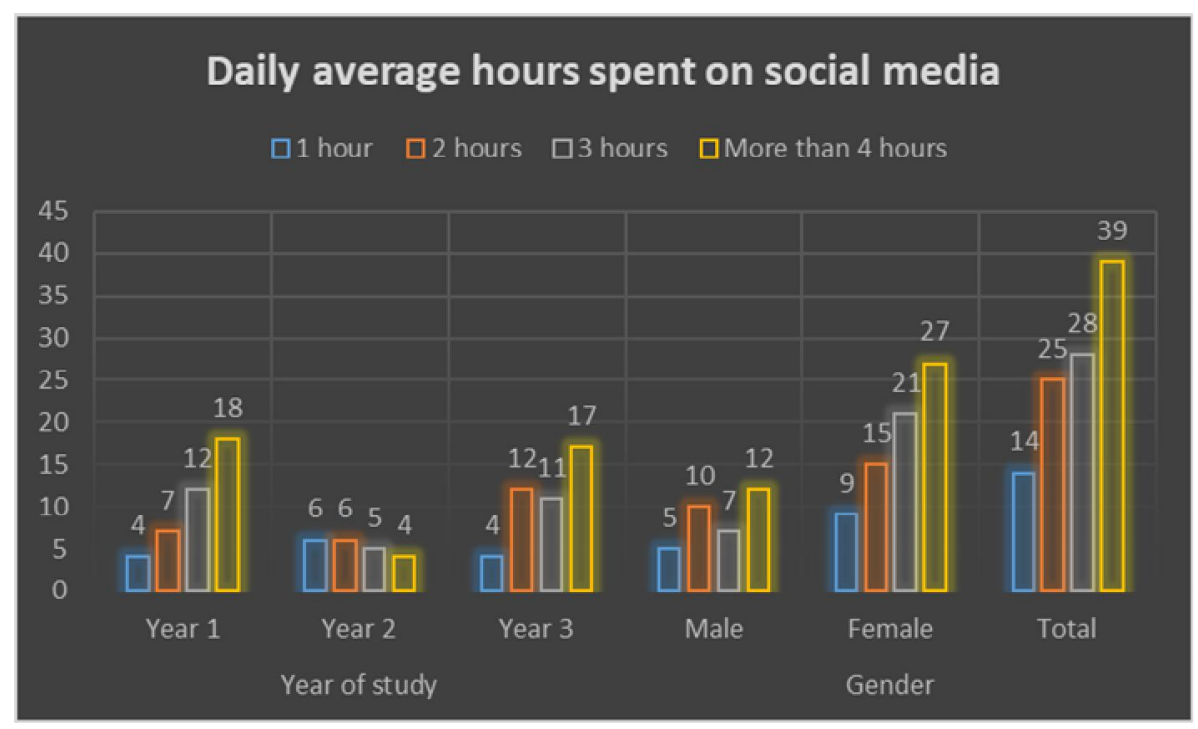

Figure 2. Daily average hours spent on social media

To back up the respondents' claims on the challenges they faced in reading, the question on the daily average hours they spent on social media was asked. Almost forty percent of the respondents said they spent more than four hours daily on average on social media: males 12 (35.3\%) and females 27 $(37.5 \%)$. In a similar study conducted to determine the effects of social media on reading habits, Anvira and Udem (2020) found that out of the total 1300 respondents, majority of them, 980 (75.3\%) said they used social media daily. This would mean that a substantial amount of time is spent on social media every day. Many researchers, therefore, attribute poor reading habits among the students to this kind of unregulated use of social media. Social media has proven to be generally addictive for tertiary students who are inclined to devote substantial amounts of their limited study time to chat, maintain social connections and make new acquaintances during their years of study (Loving and Ochoa, 2010). Florence et al. (2017) remarked "over the years, the innovation in information technology and the media have made students to read books less and get more involved in watching television, chatting online and getting more deeply engrossed in the activities in the social media" (p. 106-110). Kalpidon et al. (2011) asserted that as social media such as Facebook, YouTube, and Twitter gain popularity, they are increasingly becoming dangerous as they create modes for students to procrastinate their reading and other projects. Wang et al. (2011) researched into the effects of social media on college students. Their findings suggested that social media use is negatively associated with reading and academic performance. Further, Arthur et al. (2018) claim that tertiary students' reading culture presently is stifled by the persistent use of social media. Consequently, they have become passive readers who will rather browse. Kirschner and Karpinski (2010) noted that social media users spend fewer hours studying than nonusers. They noted that Facebook users studied 1-5 hours per week while non-users studied 11-15 hours per week. Thus, through the support of available literature, it can be concluded that the respondents' claims of 'lack of time' being the main challenge in reading cannot be true.

\section{Conclusion and Recommendations}

Although the findings revealed no notable difference in the reading habits of students from different years of study, first year students can be said to be more engaged in pleasure reading compared to senior students who are more into academic reading. Similarly, just as Thompson (1975) concluded in her study that gender has no importance in children's reading habits, no remarkable difference was found in the reading habits among male and female respondents in the current study as well. Thus, the claims that girls consistently read more than boys at every age studied (Blackwood et al., 1991; McCreath, 1975; Witty, 1961) could not be ascertained in this study. However, female students engaged more in pleasure reading than males who were more into academic reading. Unfortunately though, through informal interviews, it was found that being engaged in academic reading meant that they read only the prescribed texts. It was also found that students spend too much time on social media (average use time being identical between both boys and girls) thereby having lesser time for reading. Therefore, it can be 
confirmed that students' claim on 'lack of time' being the main challenge in reading cannot be true. It is recommended that students must cut down their time on social media to make time for meaningful readings. Students could be provided awareness workshops on the use of social media. Another important finding was, as much as with younger children, even college students looked at their tutors for inspiration and motivation. Many respondents in both survey and informal interviews said that their motivation to read depended on their tutors. It is therefore recommended that through the use of innovative ways, tutors must make concerted efforts to motivate their students to read. Tutors could undoubtedly play a pivotal role in motivating and inspiring the students to cultivate a habit of reading.

\section{References}

Akabuike, I. G \&Asika, I.E (2012). Reading Habits of Undergraduates and their Academic Performances: Issues and Perspectives. African Research Review 6 (2): 246-257.

Alexander, J.E. \& Filler, R.C. (1976). Attitudes and reading. Newark, DE: International Reading Association. https://files.eric.ed.gov/fulltext/ED126491.pdf

Anyira, I. E. \& Udem, O. K (2020). "Effect of Social Media Addiction on Reading Culture: A Study of Nigerian Students". Library Philosophy and Practice (e-journal). 4170.

Arthur, B., Agyekum, B.O., Koji, D.B (2018). Exploring the Effects of Social Media on the Reading Culture of Students in Tamale Technical University. Journal of Education and Practice 9 (7): 47-56

Askov, E.N. \& Fischbach, T.J. (1973). An investigation of primary pupils' attitude towards reading. The Journal of Experimental Education, 41(3): 1-7.

Baker, L., Scher, D., Mackler, K (1997). Home and family influences on motivations for reading. Educational Psychologist. 32 (2): 69-82

Blackwood, C, Flowers, S.S., Rogers, J.S., \& Staik, I.M. (1991). Pleasure reading by college students: Fact or fiction? Paper presented at the annual meeting of the Mid-South Educational Research Association Conference, Lexington.

Brydolf. C (2007). Minding my Space: Balancing the Benefits and Risks of Students' Online Social Networks. Education Digest. 73(2): 4-6.

Burchfield, C. M., \& Sappington, J. (2000). Compliance with required reading assignments. Teaching of Psychology, 27 (1): 58-60.

Cabral, A.P. \& Tavares, J. (2002). Practicing college reading strategies. The Reading Matrix 2(3): 1-16. www.readingmatrix.com/articles/cabral_tavares/article.pdf

Celik, B. (2019). A Study on the Factors Affecting Reading and Reading Habits of Preschool Children. International Journal of English Linguistics. 10 (1): 111-114.

Cheah, Y.M. (1998). Nurturing the Singapore readers. Reading, 32 (1): 33-34

Chettri, K., \& Rout S. K. (2013). Reading habits - An overview. IOSR Journal of Humanities and Social Science (IOSR-JHSS), 14(6): 13-17.

Clump, M.A., Bauer, H., \& Bradley, C. (2004). The extent to which psychology students read textbooks: A multiple class analysis of reading across the psychology curriculum. Journal of Instructional Psychology, 31 (3).

Coles, M. \& Hall, C. (2002). Gendered readings: Learning from children's reading choices. Journal of Research in Reading, 25(1): 96-108.

Devarajan, G. (1989). Reading interests of secondary school students. Users approach to information in libraries. New Delhi: Ess Ess.

Florence, F.O, Adesola, O.A, Hameed, B. A \&Adewumi, O.M (2017). A Survey on the Reading Habits among Colleges of Education Students in the Information Age. Journal of Education and Practice 8 (8).

Fusco, E. (1986). Reading interests and cognitive development. SIGNAL, 11(2): 1-3.

Gallik, J.D (1999). Do They Read for Pleasure? Recreational Reading Habits of College Students. Journal of Adolescent \& Adult Literacy. 42 (6): 480-488.

Greaney, B. (1986). Parental Influences on Reading. International Literacy Association and Wiley. 39 (8): 813-818

Green, P. (2002). Teacher's intervention in children's reading. Journal of Child Hood Education, 46 (3): 147-149

Gunasekara, P. W. (2002). Education in Sri Lanka. An Overview. Colombo. Deepani Printers. 
Hoeft, M. E (2012). Why University Students Don't Read: What Professors Can Do To Increase Compliance. International Journal for the Scholarship of Teaching and Learning. 6 (2): 1-19.

Jose, G.R \& Raja, B.W.D (2011). Teachers' Role in Fostering Reading Skill: Effective and Successful Reading. i-manager's Journal on English Language Teaching, 1 (4): 1-10.

Kalpidon, M., Cosin, D \& Morris, J (2011). The Relationship Between Facebook and the well-being of Undergraduate College Student Cyber Psychology Behaviour and social networking 14(4): 18318.

Kirschner, P. A., \& Karpinski, A. C. (2010). Facebook® and academic performance. Computers in human behavior, 26(6): 1237-1245.

Kush, J.C. \& Watkins, M.W. (1996). Long-term stability of children's attitudes towards reading. The Journal of Educational Research, 89(5): 315-319.

Le, T.T.H., Tran, T., Trinh, T.P.T., Nguyen, C.T., Nguyen, T.P.T., Vuong, T.T.,... Vuong, Q.H. (2019). Reading Habits, Socioeconomic Conditions, Occupational Aspiration and Academic Achievement in Vietnamese Junior High School Students. Sustainability. file:///C:/Users/user/Downloads/sustainability-11-05113.pdf

Loan, F. A. (2009). Impact of New Technology on Reading Habits: A Glimpse on the World Literature. http://eprints.rclis.org/20084/1/NCERT.pdf

Loan, F.A. (2012). Reading habits of rural and urban College students in the 21st century. Journal of Library Philosophy and Practice: Libraries at University of Nebraska, Lincoln.

Loving M. \& Ochoa, M (2010). Facebook as a Classroom Solution. New Library World. 112 (3 \& 4): 121130.

Manohar, L (2016). Impact of Reading Behaviour on Teacher Efficacy among Arts and Science College Teachers - A Predictive Model. IOSR Journal of Research \& Method in Education (IOSR-JRME), 6 (1): $13-20$

McCreath, E.E. (1975). An investigation of reading habits, reading interests, and their relationship to reading improvement of students at an urban open door junior college. In G. McNinch \& W. Miller (Eds.), Reading: Convention and inquiry (pp. 100-106). Clemson, SC: National Reading Conference

McKenna, M.C., Kear, D.J. \& Ellsworth, R.A. (1995). Children's attitudes toward reading: A national survey. Reading Research Quarterly, 30(4): 934-956.

Noor, N. M. (2011). Reading Habits and Preferences of EFL Post Graduates: A Case Study. Indonesian Journal of Applied Linguistics, I (1). http://balaibahasa.upi.edu/wp-content/uploads/2011/07/01_Noorizah-Reading_habit-edited.

Oseman, S. (1977) Factors Associated with international Students 'Academic Achievement. Journal of instructional Psychology. 24 (1): 133.

Paul, J., Baker, V., Cochran, J. (2012). Effect of Online Social Networking on Student Academic Performance. Computers in Human Behavior, 28(6): 2117-2127.

Philip, A. (2009). The Reading Habit: A Missing Link between Literacy and Libraries. https://citeseerx.ist.psu.edu/viewdoc/download?doi=10.1.1.559.5636\&rep=rep1\&type=pdf

Sainsbury, M. \& Schagen, I. (2004). Attitudes to reading at ages nine and eleven. Journal of Research in Reading, 27(4): 373-386.

Scales, A.M. \& Rhee, O. (2001). Adult reading habits and patterns. Reading Psychology, 22: 175-203.

Smith, M.C. (1990). A longitudinal investigation of reading attitude development from childhood to adulthood. The Journal of Educational Research, 83: 215-219.

Stenberg, C. (2001). Reading research in Sweden - a short survey. 67th IFLA Council and General Conference August 16-25, 2001 Boston. http://archive.ifla.org/IV/ifla67/papers/181-113e.pdf

Synder, G.V. (1981). Some patterns in reading habits of intermediate grade children. Reading-CanadaLecture, 1: 65-72.

Thompson, B. G. (1975). Sex differences in reading attainment. Educational Researcher 18: 16-23

Tobgay, T. (2016). The State of the Nation. 7th session of the second parliament of Bhutan. Thimphu

Wagner, S. (2002). The reading habits of teams. Journal of Reading Today, 46: 3-4.

Wang, Q., Chen, W., \& Liang, Y. (2011). The effects of social media on college students. https://scholarsarchive.jwu.edu/mba_student/5

Witty, P. (1961). A study of pupil's interest, grades 9, 10,11, 12. Education, 82: 100-110 
Yusof, N.M (2010). Influence of family factors on reading habits and interest among level 2 pupils in national primary schools in Malaysia. Procedia Social and Behavioral Sciences 5: 1160-1165

\section{Appendix}

\section{Reading habits Questionnaire}

Thank you for participating in the survey.

This survey is an attempt to find out the reading habits of English major students at Sherubtse College. The survey contains 16 questions. Please be as candid as possible in answering them.

Your participation would help me get the required data for the survey.

In each of the question, Please $(\checkmark)$ in the appropriate box

1. Year of study.

\begin{tabular}{|c|c|c|}
\hline $1^{\text {st }}$ year & $2^{\text {nd }}$ year & $3^{\text {rd }}$ year \\
\hline & & \\
\hline
\end{tabular}

2. Your gender

\begin{tabular}{|c|c|}
\hline Male & Female \\
\hline & \\
\hline
\end{tabular}

3. Your programme of study.

\begin{tabular}{|l|l|}
\hline BA in English & \\
\hline BA in English and Media Studies & \\
\hline BA in Dzongkha and English & \\
\hline
\end{tabular}

4. What do you think about reading? Please $(\checkmark)$ in the appropriate box

\begin{tabular}{|l|l|}
\hline It is fun & \\
\hline It is boring & \\
\hline It is time-wasting & \\
\hline It is irrelevant in the digital world & \\
\hline It is knowledge-giving & \\
\hline
\end{tabular}


5. How much time do you spend daily in reading? Please $(\checkmark)$ in the appropriate box

\begin{tabular}{|l|l|}
\hline Less than 30 minutes & \\
\hline 30 minutes to 1 hour & \\
\hline $1-2$ hours & \\
\hline More than 2 hours & \\
\hline
\end{tabular}

6. Why do you read?

\begin{tabular}{|l|l|}
\hline I need to pass my exams & \\
\hline I am forced to read & \\
\hline Reading is my passion & \\
\hline My tutors inspire me to read & \\
\hline
\end{tabular}

7. What are your challenges in reading? You can $(\checkmark)$ multiple responses

\begin{tabular}{|l|l|}
\hline Lack of time & \\
\hline Lack of reading materials & \\
\hline Lack of interest & \\
\hline Lack of motivation to read & \\
\hline
\end{tabular}

8. How has your reading habits changed after joining college?

\begin{tabular}{|l|l|}
\hline Improved & \\
\hline Deteriorated & \\
\hline Hasn't changed & \\
\hline
\end{tabular}

9. On average, how much time do you spend on social media every day?

\begin{tabular}{|l|l|}
\hline 1 hour & \\
\hline 2 hours & \\
\hline 3 hours & \\
\hline More than 4 hours & \\
\hline
\end{tabular}

Thank you for your participation. 